\title{
Impacts of the black clay soil moisture on the corrosion and cathodic protection performance of the API X70 Pipeline
}

\author{
R. Hendi ${ }^{1}$, H. Saifi ${ }^{1 *}$, K. Belmokre ${ }^{2}$, M. Ouadah ${ }^{3,4}$ \\ ${ }^{(1)}$ Laboratory of Inorganic Materials Chemistry, University Badji Mokhtar, BP 12, Annaba 23000 , \\ Algeria \\ (2) Faculty of Science, University of 20 August 1955, BP.26, Skikda 21000, Algeria \\ (3) Research Center in Industrial Technologies (CRTI), P.O. Box 64, Cheraga 16014, Algeria \\ (4) Ecole National Polytechnique, 10, av. Pasteur El Harrach, BP 182, Algiers 16200, Algeria
}

"Corresponding author e-mail address: hayettesaifi@yahoo.fr

\begin{abstract}
The impact of the black clay soil moisture of Skikda (East of Algeria), on the corrosion cathodic protection performance of the API X70 pipeline was studied in this paper. To achieve this objective, first, electrochemical analysis has been carried out. Then, in order the show impact of the black clay soil moisture of Skikda on the cathodic protection of the API X70 Pipeline, the corrosion parameters of the API X70 steel pipeline obtained by electrochemical measurements such as Tafel slopes, corrosion current densities, and corrosion potentials were used as boundary conditions in the elaborated cathodic protection model. The obtained results show that the corrosion current $I_{\text {corr }}$ is directly proportional to the moisture content up to $50 \mathrm{wt}$. $\%$, with a potential shift towards the more electronegative values. The cathodic protection perfermance has been well proven in black soil at $100 \mathrm{wt}$ \% moisture contents.
\end{abstract}

Keywords: Soil moisture, Buried Steel, Electrochemical behavior, Numerical Simulation, Cathodic Protection.

\section{INTRODUCTION}

According to National Association of Corrosion Engineer (NACE) International, corrosion is defined as the deterioration of substance or its properties because of a reaction with its environment. Many systems that in contact with soil have risk to be corroded, such as natural gas and crude oil pipelines and water mains are only some of the many structures reported to have been affected by soil corrosion all around the word [1-3] .Corrosion of steel in the soil is a complex phenomenon, with a multitude of variables involved. Some variables which affect the corrosion rate of steel in soil are water, degree of aeration, $\mathrm{pH}$, redox potential, resistivity, soluble ionic species, and microbiological activity. Soil is a heterogeneous system of porous material, with the space between particles filled with water or gases [4].The moisture content is considered to be one of the most important factors on the corrosion behavior of the soil. The increase in the moisture content leads to a decrease in the resistivity of the soil and consequently the soil becomes corrosive. With a better understanding of the main factors leading to degradation caused by the soil, corrosion of buried pipelines will be minimized. It is well known that controlling the corrosion of these buried pipeline construction materials will save the high cost of regular maintenance and replacement. To avoiding the effect of soil corrosiveness, cathodic protection is generally recommended by chemical, petrochemical and oil companies. Cathodic protection (CP) [5] is a technique used to control the corrosion of a metal surface by making it the cathode of an electrochemical cell. There are two main CP system types: the sacrificial anode $\mathrm{c}$ and the impressed current cathodic protection. Most of the reported research has investigated the corrosion behavior of steel pipelines for a specific soil type and a fixed moisture level $[6,7]$.

In order to better understand the influence of the black clay soil moisture on the corrosion and cathodic protection performance of the API X70 pipeline, measurements potentiodynamic polarization experiments were carried out. The electrochemical parameters obtained were used as boundary conditions in the model of cathodic protection developed. The results are finally discussed. 


\section{ABBREVIATIONS AND ACRONYMS}

$\beta_{a}$ : Anodic Tafel slope (V)/dec)

$\boldsymbol{\beta}_{\mathrm{c}}$ : Cathodic Tafel Tafel slope (V)/dec)

$I_{\text {corr }}$ : Corrosion Current (A)

$E_{\text {corr }}$ : Corrosion Potential (V)

$\rho$ : Soil Resistivity (s/m)

CP: Cathodic Protection

FEM: Finite Element Method

OCP : Open Circuit Potential

\section{MATERIAL AND METHODS}

\subsection{MATERIALS}

\subsubsection{MATERIALS PREPARATION}

The chemical composition of APIX70 steel used in this study is shown in Table 1.

Table 1: The chemical composition of API X 70

\begin{tabular}{llllllll}
\hline & $\mathrm{C}$ & $\mathrm{Si}$ & $\mathrm{Cu}$ & $\mathrm{Ni}$ & $\mathrm{Mn}$ & $\mathrm{Cr}$ & $\mathrm{S}$ \\
\cline { 2 - 8 } $\begin{array}{c}\text { Chemical } \\
\text { composition } \\
\text { of X70 (wt.\%) }\end{array}$ & $\mathrm{0.07}$ & 0.30 & 0.006 & 0.14 & 1.89 & 0.01 & $<0.001$ \\
\cline { 2 - 9 } & $\mathrm{Al}$ & $\mathrm{Ti}$ & $\mathrm{V}$ & $\mathrm{Nb}$ & $\mathrm{N}$ & $\mathrm{Fe}$ & \\
\cline { 2 - 9 } & 0.03 & 0.01 & 0.05 & 0.05 & 0.01 & 97.4 & \\
\hline
\end{tabular}

\subsubsection{SOIL PROPERTIES}

\section{SOIL COMPOSITION}

The specimens (black soil) used in this study are extracted from $1 \mathrm{~m}$ depth where the pipelines are usually buried in the region of the Mediterranean Sea in East of Algeria (Skikda). The soil is prepared according to the solution of $100 \mathrm{~g}$ of dried soil and 20-100 $\mathrm{ml}$ of water are prepared in a beaker, and then manually mixed using a glass stick each period of time of 30 minutes during 8 hours. The chemical composition and the physiochemical properties of the as-obtained black soil are presented in Tables 2 and $\mathbf{3}$, respectively.

Table 2: lonic composition of the black soil

\begin{tabular}{lcccccc}
\hline & $\mathrm{K}^{+}$ & $\mathrm{Na}^{+}$ & $\mathrm{Mg}^{2+}$ & $\mathrm{Ca}^{2+}$ & $\mathrm{Cl}^{-}$ & $\mathrm{P}^{+}$ \\
\cline { 2 - 7 } $\begin{array}{l}\text { lonic } \\
\text { composition } \\
(\mathrm{mg} / 100 \mathrm{~g})\end{array}$ & 0.42 & 0.37 & 2.69 & 32.72 & 2.43 & 0.58 \\
& & & & & & \\
\hline
\end{tabular}

Table 3: Physio-chemical Properties of Skikda black soil

\begin{tabular}{ccccccc}
\hline $\begin{array}{c}\text { Total } \\
\text { Carbon } \\
(\%)\end{array}$ & $\begin{array}{c}\text { Active } \\
\text { limeston } \\
(\%)\end{array}$ & $\begin{array}{c}\text { Organic } \\
\text { Matter } \\
(\%)\end{array}$ & $\begin{array}{c}\text { Conductivity } \\
(\mathrm{mS} / \mathrm{m})\end{array}$ & $\begin{array}{c}\text { Sand } \\
(\%)\end{array}$ & $\begin{array}{c}\text { Clay } \\
(\%)\end{array}$ & $\begin{array}{c}\text { Mud } \\
(\%)\end{array}$ \\
\hline 18.33 & 9.14 & 1.711 & 16.4 & 20 & 60 & 20 \\
\hline
\end{tabular}

\section{SOIL CONDUCTIVITY}

It is well-known that the conductivity can have a strong influence on the soil resistivity. Therefore in our experimental conditions, the conductivity changes according to the moisture content (Table 4).

Table 4: Black soil conductivity as a function of moisture content.

\begin{tabular}{cc}
\hline Soil moisture (wt.\%) & Soil conductivity $(\mathrm{mS} / \mathrm{cm})$ \\
20 & 70 \\
50 & 90 \\
100 & 120.4 \\
\hline
\end{tabular}

\subsection{Experimental Procedure}

\subsubsection{Electrochemical Measurements}

The potentiodynamic polarization was performed by a Bio-Logic SP-150 electrochemical workstation in a conventional three-electrode system, using a saturated calomel reference electrode (SCE), a platinum counter electrode $(\mathrm{Pt})$ and an API X70 steel sample as the working electrode (WE). The API X70 steel samples were coated with a chemically inert epoxy resin, providing an exposed surface area of 1.0 $\mathrm{cm} 2$. Before each test, the working electrode underwent abrasive paper polishing with a decreasing particle grit size from 600 to 1200 , followed by cleaning using acetone and distilled water. The potentiodynamic polarization curves were measured from the open circuit potential range, at ambient temperature, after 30 minutes of immersion.

\subsubsection{Numerical Simulation with FEM}

For diagnosing the effect of moisture content on the cathodic protection performance of API X70 steel pipelines, a cathodic protection model was simulated using the finite element method FEM is based on the corrosion parameters of the API X70 steel pipeline obtained by electrochemical measurements such as Tafel slopes, corrosion current densities and corrosion potentials. These parameters are used as limiting conditions in the CP model.

The design of the PC system requires the solution of the Laplace equation $\nabla^{2} V=0$ with the boundary conditions $(\mathrm{Tab} 4,5)$ to give the distribution of the protection potential in the pipeline. For the anode and cathode 
surfaces, the boundary conditions used were as follows:

$$
\begin{aligned}
& \text { n. } \mathrm{J}_{\mathrm{a}}=-\sigma \frac{\partial V}{\partial n}=f_{a}(\mathrm{~V}) \\
& \text { and } \\
& \text { n. } \mathrm{J}_{\mathrm{c}}=-\sigma \frac{\partial V}{\partial n}=f_{c}(\mathrm{~V})
\end{aligned}
$$

Where $J a$ and $J c$ are the current densities at the anode and cathode, respectively, and $\sigma$ is the electrolyte conductivity. $f a(V)$ and $f c(V)$ are functions that reflect the relationship between the current density and potential of the anode and cathode, respectively. The relationship between the current density and potential is generally described by a nonlinear curve, known as polarization curve obtained by electrochemical measurements.

\section{RESULTS AND DISCUSSION}

\subsection{EXPERIMENTQL RESULTS}

\subsubsection{OPEN CIRCUIT POTENTIAL}

Figure 1 illustrates that all the OCP curves fall rapidly towards the more electronegative potentials from the first moments of immersion then, begin to stabilize from the 3rd minute of the immersion. Such behavior is attributed to cathodic depolarization and an indicator of substrate degradation as a function of moisture content.

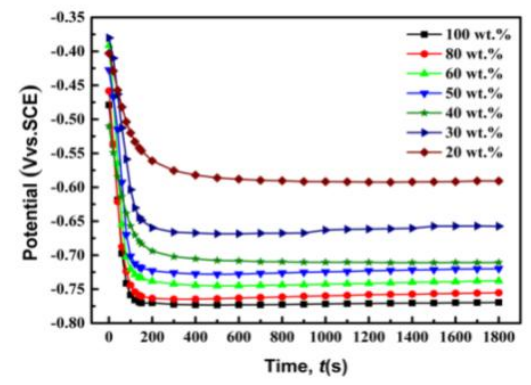

Figure 1: Evolution of the OCP potential at different moisture content.

\subsection{2.}

\section{POLARIZATION}

POTENTIO-DYNAMIC

The potentio-dynamic polarization curves of API X70 steel show for all moisture contents (Fig.2), a similar trend for the anodic zone, thus indicating an identical corrosion process, which is in good agreement with the literature $[8,9]$. Moreover, an abrupt rise of the anodic branch can be noticed, reflecting the accelerated dissolution of the metal due to the presence of oxygen in the cathodic sites and the excessive consumption of electrons produced by the anodic reaction. This phenomenon is known for metals and alloys in neutral solutions [10], where the cathodic process is mainly governed by the reduction of oxygen. Examination of the recorded cathodic branches reveals that the shape for moisture levels of 80 and 100 wt.\% differs from that of other moisture contents. This can be attributed to the cathodic activity of oxygen.

Figure 2: Potentiodynamic polarization curves of API X70 steel after exposure to soil for different moisture content.

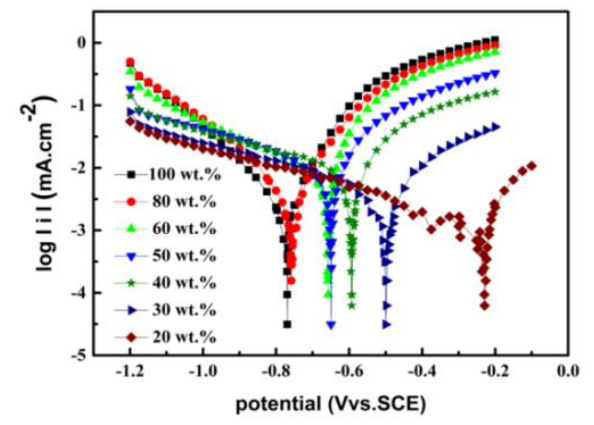

Table 5: Variation of parameters of API X70 steel after exposure to soil for different moisture content

\begin{tabular}{ccccc}
\hline $\begin{array}{c}\text { Soil } \\
\text { moisture } \\
(\mathbf{w t} \%)\end{array}$ & $\begin{array}{c}E_{\text {corr }} \\
(\mathrm{mV} . \mathrm{SCE})\end{array}$ & $\begin{array}{c}\left.\boldsymbol{I}_{\text {corr }}{ }^{2}\right) \\
\left(\mu \mathrm{A} / \mathrm{cm}^{2}\right)\end{array}$ & $\begin{array}{c}\boldsymbol{\beta}_{a} \\
(\mathrm{mV} / \mathrm{dec})\end{array}$ & $\begin{array}{c}\boldsymbol{B}_{c} \\
(\mathrm{mV} / \mathrm{dec})\end{array}$ \\
\hline 20 & -228.59 & 0.70 & 5.35 & 343.6 \\
\hline 30 & -500.61 & 2.11 & 112.3 & 212.8 \\
\hline 40 & -594.68 & 4.24 & 140.6 & 295.8 \\
\hline 50 & -649.53 & 5.70 & 111.1 & 290.8 \\
\hline 60 & -657.09 & 2.73 & 124.0 & 152.2 \\
\hline 80 & -758.63 & 1.96 & 104.1 & 135.2 \\
\hline & & & \multicolumn{3}{c}{} \\
The corrosion & current & densities are
\end{tabular}
determined by extrapolation of the cathodic and anodic Tafel lines at

the corrosion potential which are directly related to moisture content. The results exhibit a gradual increase in corrosion current density from 0.703 to $5.708 \mathrm{~mA} . \mathrm{cm}^{-2}$ for moisture content in the range 20-50 wt.\% (Tab. 5). However, beyond 50 wt.\% we recorded a small variation in the corrosion current density. Such behavior has been reported by other researchers, [11,12]. As we have noted before, for soils with low and very high moisture content, the corrosion current density values are low. In low moisture soils, the iron ions hydration is incomplete and thus 
the iron ionization in the soil becomes limited, resulting in low corrosion current density value. On the other hand, when the moisture content increases up to 50 wt.\%, the density of the corrosion current also increases to a maximum value (Tab. 5). However, as the oxygen content decreases as the soil moisture content increases, and consequently the values of the corrosion current densities decrease, it is important to note that the oxygen content of the soil decreases as the soil moisture content increases, and therefore the values of the corrosion current densities decrease. Neale et al [13], showed that the oxygen diffusion decreases significantly when the soil moisture content is near saturation, which leads to a decrease in the corrosion current densities resulting in lower corrosion rates. In our case, the reverse phenomenon is observed, with the increase of moisture content from 20 to 50 wt.\% it can be noted an increase of the corrosion current densities and consequently an acceleration of material dissolution.

\subsection{NUMERICAL SIMULATION RESULTS}

The model geometry of the cathodic protection system is a three-dimensional rectangular electrolyte volume with an anode and a cathode, as shown in (Fig. 3). In the simulation model, the electrochemical parameters revealed by the polarization curves of API X70 steel in black soil at different moisture contents are used as boundary conditions at the cathode surface. The boundary condition expresses that each point of the anode surface has the study; the potential of the sacrificial anode is -1.65 V.SCE. Because the cathodic protection by sacrificial anode, at the surface of the anode, it is assumed that the potential of the sacrificial anode is fixed.

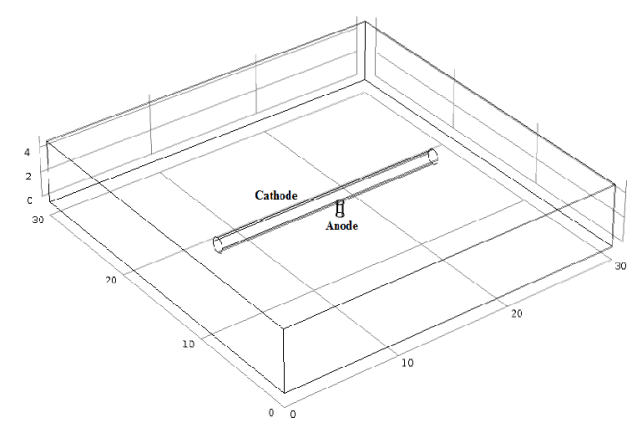

Figure 3: Model geometry of cathodic protection.
Figures 4, 5 and 6 show the contours plot of the protection current density (a) and potential protection (b), on the API X70 steel pipeline for 20,50 and 100 wt. $\%$ moisture contents, respectively. The protection potential area facing the anode has the lowest value and increases with the location away from the anode. On the other hand, the contour plot of the protection current density can clearly demonstrate that the current density area face to anode has the highest value and decreases with the location away from the anode.

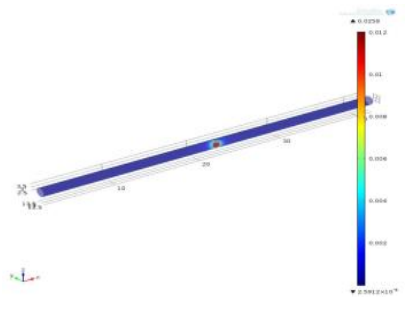

(a)

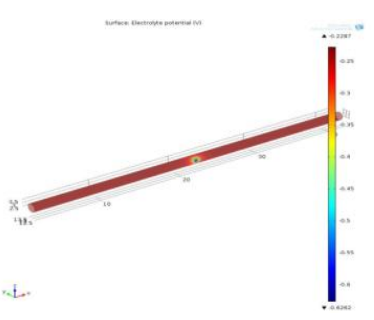

(b)
Figure 4: Cathodic protection exposure to soil with 20 wt.\% moisture content.

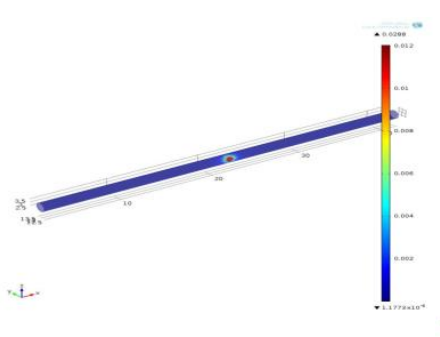

(a)

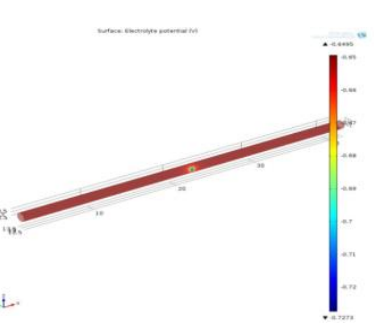

(b)
Figure 5: Cathodic protection exposure to soil with 50 wt.\% moisture content.

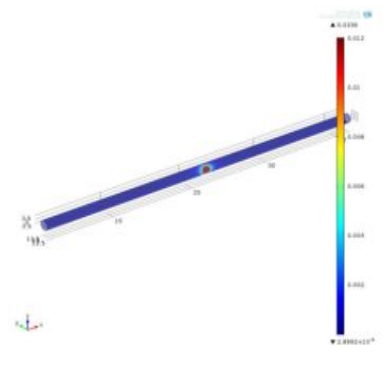

(a)

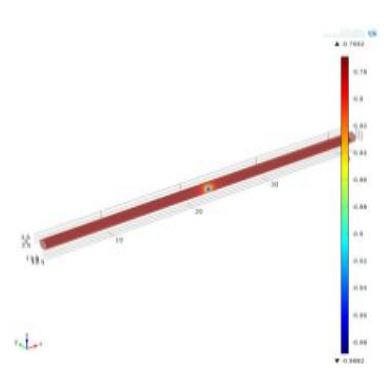

(b)
Figure 6: Cathodic protection exposure to soil with 100 wt. $\%$ moisture content. 
Figure 7 shows the distribution of the cathodic protection potential along the pipeline for 20, 50 and 100 wt.\% moisture content. From this figure, it can be seen that, the decrease of the wt.\% moisture content shifts the cathodic protection towards to the more electropositive values. According to the effective CP potential recommend- ded, for steel pipelines buried in the soil, is less than 0.780 V.SCE. It can be seen that in the case of the 100 wt. $\%$ moisture content, the protection potential is in the range of -0.9882 V.SCE and -0.780 V.SCE. Therefore, for 100 wt.\% moisture content, the pipeline is fully protected from corrosion.

On the other hand, the value 20 and 50 wt. \% moisture content shifts the CP potential from design value. Therefore, changes in soil moisture content have a significant impact on the potential and current density distribution of the pipeline (soil resistivity affects the anode output current and the pipeline protection potential becomes unstable). Although the recommended effective cathodic protection potential, for steel pipelines buried in the ground is less than 0.780 V.SCE $[14,15]$. Thus, cathodic protection is unable to maintain the potential of cathodic protection in the field of steel protection in the presence of moisture content of $50 \mathrm{wt} . \%$ and $20 \mathrm{wt} . \%$ in the soil. This means that the decrease in moisture content can cause corrosion of steel pipelines, even if there is a sacrificial anode cathodic protection system in place.

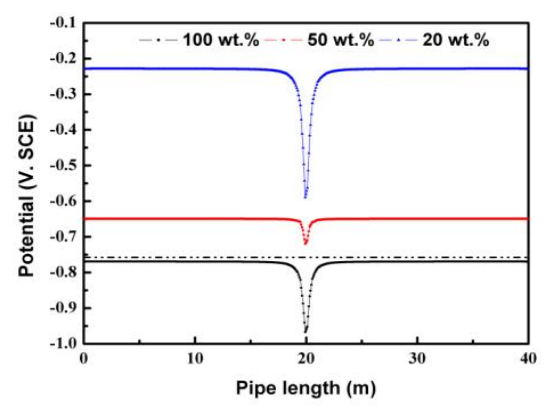

Figure 7: Protection potentiel of pipe after exposure to soil for different moisture content.

\section{Conclusion}

In this paper, the influence of black clay soil moisture content on the electrochemical behaviour of API X70 pipeline steel at ambient conditions has been investigated. The most important conclusions we have reached through this study are:
1. The OCP curves show that the higher the moisture content, the more degradation of the material occurs.

2. The polarization curves revealed that for soils with low and very high moisture content, the corrosion current density values are low, On the other hand when the moisture content up to $50 \mathrm{wt} \%$ the corrosion current density also increases to reach a maximum value. This means that the cathodic process is mainly governed by the reduction of oxygen.

3. The numerical simulation of cathodic protection by sacrificial anode showed the sacrificial role of magnesium was well determined in soil moistened at 100 wt.\%

\section{References}

[1] E. Levlin, "Corrosion of Water Pipe Systems due to Acidification of soil and Groundwater". Depart of Applied Electro Chemistry and Corrosion Science, Royal Institute of Technology, Stockholm, 1992.

[2] R.L.Starkey and K.M. Wight, "Anaerobic Corrosion of Iron in soil," Vol. 17. American Gas Association. Bullentin, 1983, pp. 11-13.

[3] A. Rim-rukehand and J.K. Awalefe, "Investigation of soil corrosivity in the corrosion of low carbon steel pipe in soil environment", Appl. Sci. Res. Vol. 2 (8), 2006, pp. 466-469.

[4] S. Wang, C.W. Du, X.G. Li, Z.Y. Liu, M. Zhu and D.W. Zhang, "Field corrosion characterization of soil corrosion of $\times 70$ pipeline steel in a red clay soil", Prog. Nat. Sci. Vol. 25 (3), 2015, pp. 242-250.

[5] M. Ouadah, O. Touhami, R. Ibtiouen, and M. Zergoug, "Method for diagnosis of the effect of $A C$ on the $X 70$ pipeline due to an inductive coupling caused by HVPL." IET Sci. Meas. Technol. Vol. 11 Iss 6, 2017, pp. 766-777.

[6] C.W. Du, X.G. Li, P. Liang, Z.Y. Liu, G.F. Jia and Y.F. Cheng, "Effects of microstructure on corrosion of X70 pipe steel in an alkaline soil", J. Mate. Engine. Perfo. Vol. 18 (2), 2009, pp. 216-220.

[7] N.A. Al-Mobarak, "Effect of oxalic acid on the dissolution of magnetite coupled with iron of various surface area," Int. J. Electrochem. Sci. Vol. 3, 2008, pp. 666-675.

[8] R.Hendi, H. Saifi, K. Belmokre, M. Ouadah et al, "Effect of black clay soil moisture on the electrochemical behavior of API X70 pipeline steel," J. Mater. Res. Express. Vol. 5, 2018, 036523.

[9] A.I.M. Ismail and A.M. El-Shamy, "Engineering behaviour of soil materials on the corrosion of mild steel," Appl. Clay Sci. Vol. 42 3-4, 2009, pp. 356-362.

[10] E.M. Sherif and S. M.Park "Effects of 1,5Naphthalenediol on aluminum corrosion as a 
corrosion inhibitor in $0.50 \mathrm{M} \mathrm{NaCl},, \mathrm{J}$. Electrochem. Soc. Vol. 152 (6), 2005, pp. B205-B2011.

[11] F. Farelas and A. Ramirez, Carbon dioxide corrosion inhibition of carbon steels through bis-imidazoline and imidazoline compounds studied by EIS," Int. J. Electrochem. Vol. 5, 2010, pp. 797-814.

[12] M. Yan, C. Sun, J. Xu, J. Dong and W. Ke, "Role of $\mathrm{Fe}$ oxides in corrosion of pipeline steel in a red caly," Mater. Corro. Scien. Vol. 80, 2014, pp. 309-317.

[13] C.N. Neale, J.B. Hughes and C.H. Ward, "Impacts of Unsaturated Zone Properties on Oxygen Transport and Aquifer Reaeration," Ground Water. Vol. 38 (5), 2000, pp.784-794.

[14] C. Liu, A. Shankar, ME. Orazem, and al. "Numerical simulations for cathodic protection of pipelines." Undergr Pipeline Corros. Vol. 63, 2014 pp. 85-126.

[15] X. Chen, H. Chen, W. Wang, L. Lin, D. Sun and L. Zhang, "Numerical Simulation of Cathodic Protection on Buried X80 steel, Sixth Internat Confer on Natur Comput (ICNC)." IEEE, 2010, pp. 4097-4099. 